\title{
MEASUREMENT OF SUN INDUCED CHLOROPHYLL FLUORESCENCE USING HYPERSPECTRAL SATELLITE IMAGERY
}

\author{
S.M. Irteza ${ }^{\text {a }}{ }^{*}$, J.E. Nichol ${ }^{\text {a }}$ \\ ${ }^{a}$ Department of Land Surveying and Geo-Informatics, The Hong Kong Polytechnic University, Kowloon, Hong Kong - \\ syedmirteza@gmail.com
}

Commission WG VIII/8

KEY WORDS: Forest stress analysis, Hyperspectral Image analysis, Sun Induced Chlorophyll Fluorescence, Hong Kong, Hyperion satellite images, Vegetation Indices

\begin{abstract}
:
Solar Induced Chlorophyll Fluorescence (SIF), can be used as an indicator of stress in vegetation. Several scientific approaches have been made and there is considerable evidence that steady state Chlorophyll fluorescence is an accurate indicator of plant stress hence a reliable tool to monitor vegetation health status. Retrieval of Chlorophyll fluorescence provides an insight into photochemical and carbon sequestration processes within vegetation. Detection of Chlorophyll fluorescence has been well understood in the laboratory and field measurement. Fluorescence retrieval methods were applied in and around the atmospheric absorption bands 02B (Red wavelength) approximately $690 \mathrm{~nm}$ and 02A (Far red wavelengths) $740 \mathrm{~nm}$. Hyperion satellite images were acquired for the years 2012 to 2015 in different seasons. Atmospheric corrections were applied using the 6S Model. The Fraunhofer Line Discrimanator (FLD) method was applied for retrieval of SIF from the Hyperion images by measuring the signal around the absorption bands in both vegetated and non vegetated land cover types. Absorption values were extracted in all the selected bands and the fluorescence signal was detected. The relationships between NDVI and Fluorescence derived from the satellite images are investigated to understand vegetation response within the absorption bands.
\end{abstract}

\section{INTRODUCTION}

Retrieval of fluorescence signal provides a unique understanding of global vegetation photosynthesis cycle as there is no specific space based observation platform measuring vegetation fluorescence (Moreno et al., 2006). Particularly, SIF is the direct indicator of canopy photosynthesis and gives quantitative measure of carbon sinks (Coops, 2015). SIF technique consider to be very fast and sensitive approach for the detection of physiological response of vegetation cover (Guanter et al., 2014). Red and far red fluorescence bands are more suitable to measure vegetation health. In Frauhonfer Line Depth (FLD) method, SIF is calculated in radiance unit by considering the Sun irradiance. Radiative properties of the leaves of the plant affect the reflectance from canopies of vegetation. Fluorescence signal can be detected in the atmospheric absorption bands (Guanter et al., 2007).

Healthy green vegetation emits chlorophyll fluorescence signal maxima in the red and far red around $690 \mathrm{~nm}$ and $740 \mathrm{~nm}$, respectively. Fruanhofer lines or oxygen absorption lines such as $\mathrm{O}_{2}$ - $\mathrm{A}$ and $\mathrm{O}_{2}-\mathrm{B}$ bands provide the main fluorescence bands. Recent studies (Goetz, 2009, Raychaudhuri, 2014a) have shown that retrieval of SIF is possible using hyperspectral images such as from the Hyperion satellite. We applied the modified FLD method using $\mathrm{O}_{2}$-A and $\mathrm{O}_{2}$-B band of Hyperion satellite images. In this study only comparisons of $\mathrm{O}_{2}-\mathrm{A}$ with the NDVI values are presented.

\section{DATA USED}

\subsection{Satellite Data}

For this project, a request for cloud free Hyperion images was submitted and eight Hyperion images were obtained (Table 1).

\begin{tabular}{|l|l|l|l|l|}
\hline Date & $\begin{array}{l}\text { Cloud } \\
\text { Cover (\%) }\end{array}$ & $\begin{array}{l}\text { Solar } \\
\text { Elevation }\end{array}$ & $\begin{array}{l}\text { Solar } \\
\text { Azimuth }\end{array}$ & $\begin{array}{l}\text { Look } \\
\text { Angle }\end{array}$ \\
\hline 3-Nov-12 & 40 & 44.514 & 143.129 & -7.697 \\
3-Dec-13 & 20 & 35.365 & 142.179 & -9.748 \\
9-Mar-13 & 10 & 46.756 & 124.254 & -10.550 \\
22-Sep-14 & 20 & 47.489 & 115.903 & -2.317 \\
8-Oct-14 & 20 & 44.202 & 123.550 & -6.360 \\
14-Feb-15 & 30 & 44.202 & 123.550 & -6.360 \\
17-Apr-15 & 20 & 46.471 & 98.922 & -6.104 \\
6-Aug-15 & 20 & 45.040 & 88.266 & -3.684 \\
\hline
\end{tabular}

Table 1: Hyperion Satellite images acquired for the retrieval of fluorescence signal.

Figure 1 shows the Hyperion image over Hong Kong region. 10 sample sites were also shown over the image at different sites in the Hong Kong country parks.
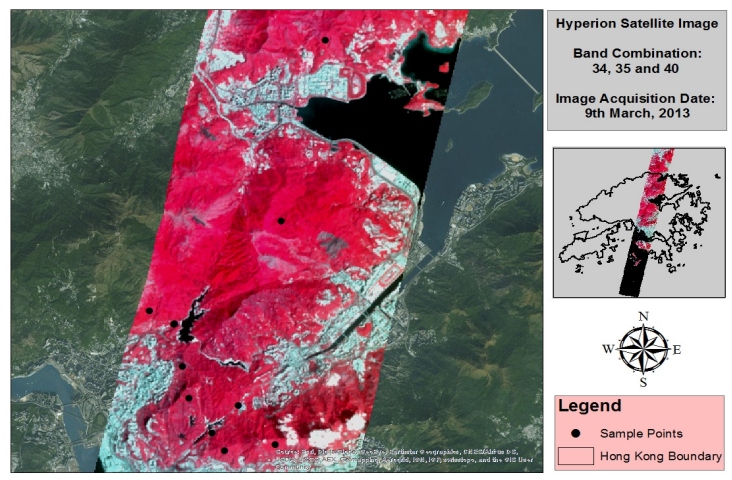

Figure 1: Hyperion Image of Hong Kong Region 


\section{METHODOLOGY}

\subsection{Satellite Data Pre-processing}

To investigate the fluorescence, L1Gst Product of Hyperion was converted into surface reflectance using $6 \mathrm{~S}$ method. Atmospheric correction model $6 \mathrm{~S}$ proved to give most suitable results over all surfaces in the Hong Kong region (Nazeer et al., 2014). For SIF based fluorescence retrieval, we selected 6 bands. For $\mathrm{O}_{2}$-fluorescence retrieval B33, B34, B35 were used as shown in Table 2.

\begin{tabular}{|l|l|l|l|}
\hline $\begin{array}{l}\text { Hyperion } \\
\text { Band }\end{array}$ & $\begin{array}{l}\text { Average } \\
\text { Wavelength } \\
(\mathrm{nm})\end{array}$ & $\begin{array}{l}\text { Full Width at } \\
\text { Half the } \\
\text { Maximum } \\
\text { FWHM (nm) }\end{array}$ & $\begin{array}{l}\text { Spatial } \\
\text { Resolution } \\
(\mathrm{m})\end{array}$ \\
\hline B33 & 681.2000 & 10.3349 & 30 \\
\hline B34 & 691.3700 & 10.3909 & 30 \\
\hline B35 & 701.5500 & 10.4592 & 30 \\
\hline
\end{tabular}

Table 2: Hyperion Selected Band Central Wavelength

\subsection{Retrieval of Sun Induced Fluorescence (SIF)}

SIF in the $\mathrm{O}_{2}$-A and $\mathrm{O}_{2}$-B spectral wavelength regions was retrieved using the FLD method after applying preprocessing tasks. For this we selected 10 sites based on canopy cover (CC) of forest $(\mathrm{CC}>75 \%)$. A total of 10 non vegetated sites near to the vegetated sites were also selected.

The fluorescence signal was retrieved from both vegetated and non vegetated sites by calculating difference at sensor radiance inside and outside for the $\mathrm{O}_{2}-\mathrm{A}$ and $\mathrm{O}_{2}-\mathrm{B}$ absorption waveband and which can be expressed as three wavelengths inside and outside the band (Equation 1) (Raychaudhuri, 2014)

$\mathrm{D}=\omega_{\mathrm{L}} \mathrm{L}_{\mathrm{L}}+\omega_{\mathrm{R}} \mathrm{L}_{\mathrm{R}}-\mathrm{L}_{\mathrm{F}}$

Whereas, $\mathrm{D}=$ Difference in radiance and has unit $\left(\mathrm{Wm}^{-2} \mathrm{sr}^{-1}\right.$ $\mu \mathrm{m}^{-1}$ )

$\lambda_{\mathrm{F}}=$ Fluorescence wavelength

$\mathrm{L}_{\mathrm{L}=}$ Radiance values at wavelengths $\lambda \mathrm{L}$

$\mathrm{L}_{\mathrm{R}}=$ Radiance values at wavelengths $\lambda \mathrm{R}$

$\mathrm{L}_{\mathrm{F}}=$ Radiance corresponding to the wavelength $(\lambda \mathrm{F})$

| $\omega_{\mathbf{L}}$ and $\boldsymbol{\omega}_{\mathbf{R}}$ are the relative weights of the absorption bands and represented by the following equations (2) and equation (3)

$\omega_{\mathrm{L}}=\frac{\lambda_{\mathrm{R}}-\lambda_{\mathrm{F}}}{\lambda_{\mathrm{R}}-\lambda_{\mathrm{L}}}$

and

$$
\omega_{R}=\frac{\lambda_{F}-\lambda_{L}}{\lambda_{R}-\lambda_{L}}
$$

On each sample site windows of 5 X 5 pixels were generated and the average was taken. Fluorescence values were retrieved as a percentage i.e the fluorescence emission contribution of vegetation, estimated as a percentage of the average reflected radiance for vegetation outside the absorption band. All the reported results are normalized for comparison purposes. By comparing the fluorescence retrieved value with the NDVI value in different seasons and in different years, an understanding of fluorescence retrieval method at local scale has been presented.

\section{RESULTS}

\subsection{NDVI Extraction}

We summarize our results according to four seasons which are;

(a) December, January, February (Winter season, DJF)

(b) March, April, May (Spring, MAM)

(c) June, July, August (Summer, JJA)

(d) September, October, November (Autumn, SON)

All ten vegetated sites were selected in each image which showed NDVI values greater than 0.5. Figure 2 shows that in winter and spring season, NDVI value was equal to or greater than 0.6 in most of sites.

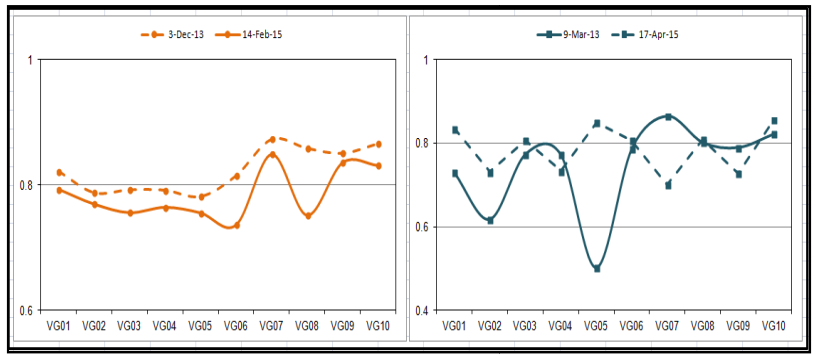

Figure 2: Normalized Difference Vegetation Index (NDVI) calculated for the Hyperion images acquired over different seasons (a) - Winter (DJF), (b) - Spring (MAM)

\section{2 $\mathrm{O}_{2} \mathrm{~A}$ Fluorescence}

The pattern of fluorescence signal is shown in Figure- 2 for $\mathrm{O}_{2^{-}}$ A band for all the months at 10 different sites.

For Winter (DJF) decreased fluorescence response is observed throughout the $\mathrm{O}_{2}$-A band except at sites 2 and 6 , where a sudden increase in fluorescence signal is detected. In Spring (MAM) the fluorescence signal shows similar a trend again at all the selected sites in $\mathrm{O}_{2}$-A except at the site 9 where an increase in $\mathrm{O}_{2}-\mathrm{A}$ band was detected. For Summer (JJA), an increase in fluorescence for $\mathrm{O}_{2}$-A band at site 9 was detected. In Autumn season ( $\mathrm{SON}$ ) at site 3 there is an increase in fluorescence signal in $\mathrm{O}_{2}$-A Band.

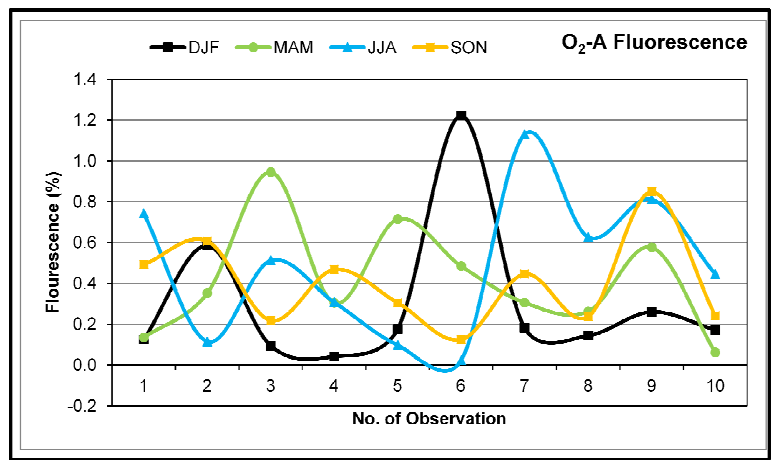

Figure 3: Chlorophyll fluorescence intensity for different seasons obtained from O2-A bands of Hyperion. 


\subsection{Relationship Between NDVI and SIF for $\mathrm{O}_{2} \mathrm{~A}$ Band}

For the purpose of the validation of the fluorescence value and to observe the trend of both NDVI and fluorescence, a comparison between NDVI and Fluorescence were also performed as shown in Figure 4. It showed that at site 3 and site 9 correlation between both NDVI and fluorescence is around 0.03 and 0.06 respectively which is very low despite of the fact that the highest NDVI value is detected on both sites. For site 5 and site 8 highest correlations were detected between NDVI and fluorescence. Some other factors might affect the retrieved fluorescence value. Those reasons might include AOD high values, soil contamination and any other variable effecting the retrieval of fluorescence value.

Figure 4: Relationship between NDVI and Fluorescence derived using O2A bands of Hyperion from 2012 to 2015 for sites ten vegetation sites

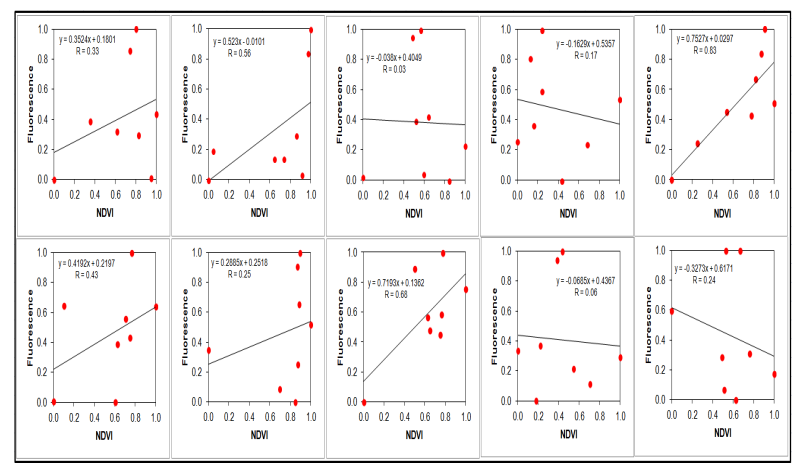

\section{CONCLUSIONS}

Retrieval of chlorophyll fluorescence was performed by applying the FLD method. The fluorescence results were then compared with the NDVI values. Based on the established theory, fluorescence should behave linearly with the NDVI values but error should be expected if atmospheric parameters such as water vapour and aerosols were not eliminated with great care and accurate measured values. Preliminary results suggest that SIF correlates highly with NDVI at some selected sites and on some sites, a very low correlation exhibit between SIF and NDVI. Next phase of this study will consider possibility of analyzing rainfall data and field spectrometer data to see any possible cause of these variations. Fluorescence retrieval from $\mathrm{O}_{2}$-A bands from the Hyperion image and its relation between NDVI values shows that the correlation is within acceptable range which solidified the basic methodology.

\section{REFERENCES}

Coops, N. C., 2015. Characterizing Forest Growth and Productivity Using Remotely Sensed Data. Current Forestry Reports.

Goetz, A. F. H., 2009. Three decades of hyperspectral remote sensing of the Earth: A personal view. Remote Sensing of Environment, 113(2009), S5-S16.

Guanter, L., Alonso, L., Gómez-Chova, L., Amorós-López, J., Vila, J., \& Moreno, J., 2007. Estimation of solar-induced vegetation fluorescence from space measurements. Geophysical Research Letters, 34(8), L08401.
Guanter, L., Zhang, Y., Jung, M., Joiner, J., Voigt, M., Berry, J. a, ... Griffis, T. J., 2014. Global and time-resolved monitoring of crop photosynthesis with chlorophyll fluorescence. Proceedings of the National Academy of Sciences of the United States of America, 111(14), E1327-33.

Moreno, J. F., Asner, G. P., Bach, H., Belenguer, T., Bell, A., Buschmann, C., ... Court, A., 2006. FLuorescence EXplorer ( FLEX ): mapping vegetation photosynthesis from space, pp. 832-837.

Nazeer, M., Nichol, J. E., \& Yung, Y., 2014. Evaluation of atmospheric correction models and Landsat surface reflectance product in an urban coastal environment. International Journal of Remote Sensing, (April 2015), pp. 37-41.

Raychaudhuri, B., 2014a. Solar-induced fluorescence of terrestrial chlorophyll derived from the $\mathrm{O} 2$-A band of Hyperion hyperspectral images. Remote Sensing Letters, 5(11), pp. 941-950. 